\title{
Peticiones de asilo basadas en cuestiones de sexualidad: algunas respuestas y muchas preguntas
}

Este comentario, junto a los documentos que analiza, está disponible en www.anuariocdh.uchile.cl

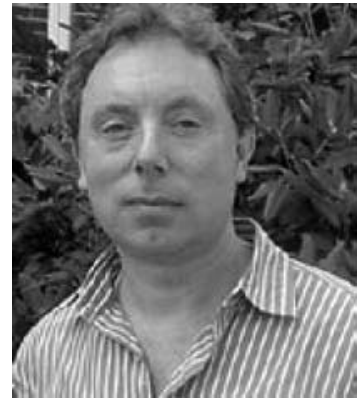

\begin{abstract}
Daniel Kanstroom
Director del Programa Internacional de Derechos Humanos y Profesor Titular de Derecho de la Escuela de Derecho de Boston College. Dirige los programas de Tribunal Penal Internacional del Boston College en La Haya y en Sarajevo. Actualmente se desempeña como Profesor Invitado de la American University habiendo ejercido la docencia anteriormente en la Universidad de París, en la Facultad de Derecho de la Universidad Northeastern, la Universidad de Boulogne sur Mer, King's College de la Universidad de Londres, la Universidad de Hawai'i, y la Vermont Law School. El Profesor Kanstroom es miembro de la Comisión Nacional de Inmigración del Colegio de Abogados de EE.UU. (American Bar Association) y durante largo tiempo ha integrado el Directorio del Proyecto PAIR (Proyecto de Representación para el Asilo Político y la Inmigración).

kanstroo@bc.edu
\end{abstract}

\section{RESUMEN}

Actualmente muchos sistemas legales aceptan que las personas gay, lesbianas, bisexuales y transexuales ("LGBT") también pueden obtener asilo, nonrefoulement o que se declare temporalmente su no devolución (según las leyes de EE.UU.) o protección judicial conforme a la Convención contra la Tortura debido a su orientación o comportamiento sexual. Ya sea que uno considere este hecho como un suceso revolucionario o como el desarrollo natural de los derechos humanos y el derecho de los refugiados, evidentemente quedan muchas preguntas sin responder. El artículo destaca y evalúa algunas de las principales interrogantes y tensiones existentes en el estado actual de la legislación, en particular el hecho de que el tema del asilo basado en la orientación sexual de la persona implica muchas de las más profundas tensiones que yacen debajo de la superficie del derecho de los derechos humanos en general como también del derecho de refugio y de asilo.

\section{Casos y tendencias}

En la actualidad es generalmente aceptado -al menos en ciertos círculos- que las personas lesbianas, gay, bisexuales y transexuales ${ }^{1}$ ("LGBT") pueden obtener asilo ${ }^{2}$, nonrefoulement o que se declare

1 El término "transexual" se utiliza en este artículo para referirse, en términos muy generales y extremadamente simplificados, a personas cuya identidad de género y/o expresión de género difiere del sexo que le fue asignado al nacer.

2 Ver, por ejemplo, Sentencia del 26 de abril de 1983, № IV/I E 06244/81 Verwaltungsgericht Wiesbaden (que revierte la negativa del organismo de dar asilo a un hombre gay de Irán y estimar que la sociedad iraní percibe a los homosexuales como un grupo paria y, por consiguiente, que constituyen un "determinado grupo social") (descrito en Fullerton, M. A Comparative Look at Refugee Status based on Persecution Due to Membership in a Particular Social Group. 26(3): 533-535. 1993. Cornell International Law Journal; ver también Matter of Toboso-Alfonso, 20 I\&N Dec. 819 (1990) (designado como precedente el 16 de junio de 1994) (una persona identificada como homosexual y perseguida por su propio gobierno, por esa sola razón, podría ser considerada con derecho a reparación en virtud del derecho internacional de los refugiados por persecución por pertenencia a un determinado grupo social); Pitcherskaia v. INS, 118 F.3d 641 (9 $9^{\text {th }}$ Cir. 1997); Hernández-Montiel v. INS, 225 F.3d 1084 (9 $9^{\text {th }}$ Cir. 2000). 
temporalmente su no devolución (según las leyes de EE.UU.), o protección judicial conforme a la Convención contra la Tortura ${ }^{3}$, debido al perjuicio que pudieran sufrir a consecuencia de su orientación o comportamiento sexual ${ }^{4}$. La cuestión básica de si dichas peticiones -basadas en la orientación sexual o la identidad de género- pueden ser sometidas al conocimiento judicial, ha recibido respuesta afirmativa en una gran variedad de $\operatorname{casos}^{5}$. Los tribunales superiores y de primera instancia de Australia, Canadá, Nueva Zelanda, Sudáfrica, Estados Unidos y Europa han reconocido explícitamente que la persecución basada en la orientación sexual o la transexualidad de la persona constituye una base legítima para el asilo ${ }^{6}$.

Ya sea que uno considere este desarrollo como revolucionario, o bien como una aplicación natural de principios que desde antiguo han sido considerados como inherentes a los derechos humanos y el derecho internacional de los refugiados ${ }^{7}$, este tema deja aún muchas preguntas por responder. Algunas de las interrogantes parecen ser técnicas, específicas y más bien propias de la doctrina jurídica sobre el asilo y los refugiados ${ }^{8}$. Por ejemplo, ¿cómo debiera definirse la categoría de "determinado grupo social" establecida en la Convención sobre el Estatuto de los Refugiados de 1951? ¿Puede la discriminación o el "perjuicio económico" entenderse como una "persecución" (en los términos de dicha Convención) en contra de los gay que procuran obtener asilo? ${ }^{9}$ Pese a su carácter técnico, esta clase de preguntas implica profundas tensiones en las estructuras de las

3 Ver Reyes-Reyes v. Ashcroft, 384 F.3d 782 (9th Cir. 2004) (si un gobierno ignora deliberadamente el grave abuso físico infligido por actores no gubernamentales a un "hombre gay con una identidad sexual femenina", ello puede llegar a constituir aquiescencia del gobierno ante la tortura, y calificar para la reparación según la Convención contra la Tortura y para que se suspenda la devolución); Ornelas Chávez v. González, 458 F.3d 1052 (9th Cir. 2006) (la remisión del expediente de una mujer transexual de México que fue víctima de abusos de la familia y de sus compañeros de trabajo, porque el juez de inmigración aplicó criterios jurídicos inaceptablemente estrictos para rechazar peticiones para aplazar la devolución que invocaba la Convención contra la Tortura (CCT)); Morales v. González, 472 F.3d 689 (9th Cir. 2007) (IJ erró al denegar la petición basada en CCT al no tomar en cuanta la "deliberada ceguera" de los funcionarios gubernamentales; sufrir una agresión sexual en prisión, bajo la vigilancia de los guardias, reunía los requisitos legales para la protección judicial bajo las normas de la CCT).

4 Ver, UNHCR Guidance Note on Refugee Claims Relating to Sexual Orientation and Gender Identity, 21 de noviembre de 2008; J. MILBANK, The Role of Rights in Asylum Claims Based on Sexual Orientation, Human Rights Law Review, vol. 4, pp. 193-228, 2004.

5 En efecto, incluso la identidad sexual percibida podría ser suficiente. Ver Amanfi v. Ashcroft, 328 F.3d 719 (3rd Cir. 2003) (se trataba de una petición de asilo fundada en la persecución debido a la atribución de pertenencia a un determinado grupo social basado en la orientación sexual, incluso si el peticionario no es gay en realidad).

6 Ver, en general, OTTOSSON, D. State-Sponsored Homophobia: A World Survey of Laws Prohibiting Same-Sex Activity Between Consenting Adults. [En Línea] International Lesbian \& Gay Association. Abril, 2007 <http://www.ilga.org/ statehomo phobia/State sponsored homophobia ILGA 07.pdf>; WALKER, K. Sexuality and Refugee Status in Australia. International Journal of Refugee Law. 12(2):180-184. Julio, 2000; Egan v. Canada, [1995] 2 S.C.R. 513,175 (Can.).

7 Ver, por ejemplo, Millbank, supra (donde se señala que la orientación sexual "en general, dista mucho de ser aceptada comúnmente como base para efectuar peticiones de igualdad en muchas de las naciones que reciben a los refugiados" y sugiere que "un mayor conocimiento de las peticiones de las lesbianas y los gay en una serie de áreas junto con un compromiso más duradero y profundo con el análisis de la igualdad, ha significado que los responsables de tomar decisiones en Canadá... han estado más dispuestos a vincular las demandas basadas en la orientación sexual con las normas de derechos humanos"); ver también, BHABHA, J. Internationalist Gatekeepers?: The Tension Between Asylum Advocacy and 15 Human Rights. Harvard Human Rights Journal. 15:155-164. 2002, que contiene una discusión más seria acerca de las relaciones entre el asilo y el derecho internacional de los refugiados y el movimiento de los derechos humanos.

8 Ver, por ejemplo, Bromfield v. Mukasey,_F.3d_(9th Cir. 2008) (determina que hay un patrón y una práctica de persecución en contra de los homosexuales en Jamaica; y ordena la remisión al tribunal de primera instancia para que determine si la persecución satisface o no los requisitos para que se declare temporalmente la no devolución).

9 Ver Kadri v. Mukasey,__F.3d_(1st Cir. 2008) (remisión de una solicitud de asilo de un hombre gay de Indonesia para que el Comité de Apelaciones de Inmigración (BIA, por sus siglas en inglés) estableciera el criterio para determinar que hay persecución económica). 
leyes de asilo y en la evolución del propio movimiento de derechos humanos ${ }^{10}$. Como observa un estudio reciente, gran parte de la comunidad internacional "continúa negando a los homosexuales, bisexuales y otras minorías sexuales, muchas de las protecciones que establecen las normas de derechos humanos ${ }^{\prime 11}$. Las razones que motivan esta actitud deben exponerse francamente: "las elites políticas o sus electores... se sienten ofendidas por la sexualidad no convencional, por razones religiosas y culturales"12. En consecuencia, "sigue siendo común la persecución sistemática, pública y privada, de las minorías sexuales en todo el mundo"13. Por consiguiente, las peticiones de asilo basadas en cuestiones de sexualidad continúan siendo tremendamente desafiantes, a pesar del progreso alcanzado hasta ahora en el campo de los derechos humanos. Este breve artículo no pretende ser un análisis integral sobre este tema. Simplemente pretendo destacar y evaluar lo que estimo como algunas de las mayores interrogantes y tensiones en el estado actual del derecho internacional.

Como la legislación europea se ha adelantado a la de Estados Unidos, podría ser más útil comenzar por el examen de algunas de las tensiones que persisten en aquélla. Tomemos dos casos recientes y la discusión pública que provocaron en el Reino Unido. Mehdi Kazemi, un adolescente iraní gay, fue a Londres a estudiar inglés. Más tarde se enteró de que su pareja había sido arrestada por la policía iraní, acusada de sodomía y ejecutada en la horca. Luego que supo que, antes de su ejecución, su pareja había sido interrogada acerca de sus relaciones sexuales con otros hombres y que lo había mencionado, el señor Kazemi pidió asilo ${ }^{14}$. En el año 2007 su caso fue rechazado inicialmente y huyó de Gran Bretaña hacia los Países Bajos, donde su caso fue denegado por las autoridades neerlandesas y se vio obligado a regresar al Reino Unido ${ }^{15}$.

En una carta pública, dirigida a Jacqui Smith, Ministra del Interior, el señor Kazemi describió su caso como uno en que "la situación en mi país ha cambiado. Las autoridades iraníes descubrieron que soy homosexual y me están buscando". Describió su orientación sexual de manera conmovedora y en términos extraordinariamente defensivos: "No puedo detener mi atracción por los hombres. Esto es algo con lo que voy a tener que vivir el resto de mi vida. Nací con este sentimiento y no

10 Ver, por ejemplo, International Commission of Jurists (ICJ). Sexual Orientation and Gender Identity in Human Rights Law: References to Jurisprudence and Doctrine of the United Nations Human Rights System. [En Línea] $3^{\text {a }}$ edición actualizada, 2007. <http://www.icj.org/IMG/UN_References.pdf>; International Commission of Jurists (ICJ). Sexual Orientation and Gender Identity in Human Rights Law: Jurisprudential, Legislative and Doctrinal References from the Council of Europe and the European Union. [En Línea] Octubre de 2007. <http://www.icj.org/European_Compilationweb.pdf>; e, International Commission of Jurists (ICJ). Sexual Orientation and Gender Identity in Human Rights Law: References to Jurisprudence and Doctrine of the Inter-American System. [En Línea] Julio de 2007. <http://www.icj.org/ IMG/Inter-American_References.pdf>. Ver también, Yogyakarta Principles on the Application of International Human Rights Law in Relation to Sexual Orientation and Gender Identity. [En Línea] 2007. <http://www.yogyakartaprinciples. org/principles_en.htm> Principios 22 (derecho a la libertad de movimiento) y 23 (derecho a pedir asilo)

11 FELLMETH, A. State Regulation of Sexuality in International Human Rights Law and Theory. William \& Mary Law Review. 50:797, 800. 2008.

12 ld.

13 ĺd. en 843.

14 Ver VERKAIK, R. A life or death decision. [En Línea] The Independent, 6 de marzo de 2008. <http://www.independent. co.uk/news/uk/home-news/a-life-or-death-decision-792058.html>

15 En virtud de la llamada Regulación II de Dublín, que establece una jerarquía de criterios para identificar el Estado miembro de la Unión Europea responsable de procesar una petición de asilo que, como en este caso, generalmente significa que lo es el Estado por el cual ingresó por primera vez a la UE la persona que pide asilo. Ver Council Regulation (EC) No 343/2003, del 18 de febrero de 2003, que establece los criterios y mecanismos para determinar cuál es el Estado miembro responsable de examinar una solicitud de asilo presentada en alguno de los estados miembro por un nacional de un tercer país. 
puedo cambiarlo...". Kazemi temía que, si se le obligaba a volver a Irán, lo iban a "arrestar y ejecutar como a mi ex pareja"16.

El caso atrajo gran atención de la prensa e intensas críticas. Peter Tatchell, miembro de Outrage, un grupo pro derechos de los gay, definió la negativa inicial del gobierno como "indignante y vergonzosa". Sostuvo que si se enviaba a Kazemi de regreso a Irán corría el riesgo de ser ejecutado por causa de su homosexualidad, lo que constituiría "una violación flagrante de las obligaciones de Gran Bretaña según la Convención sobre los refugiados"17.

El caso planteó profundas interrogantes sobre la identidad versus la conducta. Un febril debate siguió a la afirmación de Jacqui Smith, en una carta a un colega, de que los gay y las lesbianas que desean obtener asilo podían ser deportados a Irán sin riesgo mientras vivieran sus vidas "discretamente". Supuestamente, Smith escribió que no habría un "riesgo real" de que las autoridades iraníes descubrieran a los hombres gay y las mujeres lesbianas ni de que se tomara una "acción adversa" en contra quienes fueren "discretos" acerca de su "orientación sexual"18. Ben Summerskill, Director Ejecutivo de la organización pro derechos gay llamada Stonewall, respondió diciendo que: "Basta con escuchar a las personas que fueron aterrorizadas por la Policía Metropolitana en los años cincuenta y sesenta para saber que es quijotesco decirle a las personas gay que vivan discretamente ${ }^{\prime 19}$. Además, el caso destaca el contenido ambivalente de muchas normas sobre derechos humanos respecto del principio de la no discriminación, en cuanto a su aplicación a la orientación sexual ${ }^{20}$. Por una parte, en el sistema europeo, las medidas restrictivas de derechos que pueden adoptarse para la protección de la moral pública y la seguridad social deben responder a una "necesidad social apremiante" y ser "proporcionales al objetivo legítimo que se busca"21. En contraste, una ley nicaragüense del año 1992 castiga no sólo ciertas conductas, sino incluso la "inducción, promoción y realización de propaganda" de las relaciones sexuales entre personas del mismo sexo ${ }^{22}$. Varios otros países mantienen normas similares ${ }^{23}$.

Aún así, la tendencia en contra de la criminalización ha sido clara en Europa. Desde el año 2003 Europa no ha tenido leyes que penalicen las relaciones sexuales consensuadas entre personas adultas del mismo sexo ${ }^{24}$. Por lo tanto, las críticas a las políticas de asilo del gobierno del Reino Unido vienen tanto de la derecha como de la izquierda. El parlamentario conservador Stephen Crabb, presidente del Comité de Derechos Humanos del Partido Conservador, señaló que: "La mayoría de las personas justas estarán consternadas ante la declaración de la Ministra del Interior. El régimen iraní tiene un historial horroroso en lo concerniente al trato de los homosexuales y otros grupos minoritarios, y está más que dispuesto a usar la tortura y la sentencia de muerte para

\footnotetext{
16 Ver VERKAIK, supra.

17 Íd. Según algunos defensores iraníes de los derechos humanos, más de 4.000 hombres gay y lesbianas han sido ejecutados desde el año 1979. Íd.

18 VERKAIK, R. Fury as Smith says Iran is safe for "discreet" gays. [En Línea] The Independent, 23 de junio de 2008. <http:// findarticles.com/p/articles/mi_qn4158/is_20080623/ai_n27514586>

19 ld.

20 Ver Carta de Derechos y Libertades Fundamentales de la Unión Europea, art 21, 2000 O.J. (C364) (derechos específicos de no discriminación basados en la orientación sexual o estatus minoritario).

21 Ver Smith \& Grady v. United Kingdom, 29 Eur.H.R.Rep 493 (2000); Lustig-Prean \& Beckett v. United Kingdom, 29 Eur.H.R.Rep 548 (1999); Norris v. Ireland, 13 Eur.H.R.Rep 186; Dudgeon v. United Kingdom, 4 Eur.H.R.Rep 149 (1982); ver FELLMETH, supra, 806-810.

22 FELLMETH, supra, en 812.

23 Ver, en general, OTTOSSON, D., supra; International Lesbian \& Gay Association. World Legal Survey. <http://www.ilga. org>

24 Íd. en 814. (Armenia fue el último país en derogar dichas leyes).
} 
castigar a los infractores". Crabb continuó indicando que: "Pedirle a las minorías que vivan sus vidas discretamente es rendirse ante los tiranos y matones que mantienen sus posiciones gracias a la conformidad lograda mediante el miedo y la coerción. Ello demuestra tanto una pobre opinión de la importancia de los derechos humanos, como cobardía para defender nuestro propio sistema de valores".

En un rápido vuelco, en mayo de 2008, se le otorgó a Kazemi "autorización para permanecer" por cinco años ${ }^{25}$. Ben Summerskill dijo que: "Estamos encantados y muy agradecidos con Jacqui Smith por su intervención...". También se manifestó complacido de que "los funcionarios del Ministerio de Relaciones Exteriores hayan reconocido el peligro que enfrentan las personas gay en Irán" ${ }^{26}$. Sin embargo, el alcance de la victoria sigue siendo poco claro. Como observara Peter Tatchell: "Mehdi no habría obtenido la autorización de permanencia si su caso no hubiese tenido enorme publicidad. Hay muchos otros gay y lesbianas iraníes que han solicitado asilo y que están en lista para ser deportados a Irán" 27 . En realidad, el problema está mucho más extendido aún. Según un investigador, las relaciones sexuales entre personas del mismo sexo siguen siendo sancionadas penalmente en 41 estados-nación para las mujeres y en 81 estados-nación para los hombres ${ }^{28}$. De hecho, se estima que la tercera parte de la población mundial sigue estando sometida a tales leyes y políticas ${ }^{29}$. Al menos siete países imponen aún la pena de muerte para las conductas homosexuales ${ }^{30}$.

Otro caso reciente del Reino Unido planteó temas similares, junto con aspectos de carácter más técnico ${ }^{31}$. A un hombre de nacionalidad siria, Jojo Jako Yakob, se le denegó el derecho a permanecer en Escocia, pese a que el gobierno aceptó que es gay y que en Siria se penaliza y reprime la homosexualidad. Yakob, un cristiano kurdo, había huido al Reino Unido luego de ser arrestado por distribuir panfletos en contra del gobierno. Cuando los guardias de la prisión descubrieron que era homosexual, se informa que fue golpeado y agredido físicamente de manera tan severa que cayó en coma. La sentencia en su caso acepta que "Siria penaliza y reprime la homosexualidad". Sin embargo, agrega que: "Los homosexuales deben modificar su comportamiento y estilo de vida tomando esta circunstancia en cuenta. No hallamos razones para suponer que en Siria [Yakob] se conduciría de otro modo que no sea discretamente para evitar repercusiones" ${ }^{32}$. Yakob respondió públicamente: "Pero, ¿cómo se vive? Esa no es vida. Quiero vivir mi vida y ser libre, y no podría hacer eso en Siria" ${ }^{\prime 3}$. Como elemento adicional a la complejidad del caso, el Tribunal había estimado que ciertas pruebas de Yakob eran "contradictorias entre sí y poco confiables". Aún así, Peter Tatchell Ilamó a la negativa de otorgar asilo "irracional, equivocada e insensible". Sugirió

25 CNN. Gay Iranian wins UK asylum fight. [En Línea] CNN Internacional, 20 de mayo de 2008. <http://www.cnn.com/2008/ World/europe/05/20/iran.gay.uk/index.html>

26 Pinknews. Praise for Home Secretary as Mehdi Kazemi granted asylum in UK. [En Línea] PinkNews. 20 de mayo de 2008. <http://www.pinknews.co.uk/news/articles/2005-7687.html>

27 Ver Gay Pride marchers plan asylum protest. The Independent. Londres, Inglaterra, 5 de julio de 2008. (los gay y lesbianas que asisten hoy a la marcha del Orgullo Gay en Londres piensan protestar en contra del trato dado por el gobierno a las personas que piden asilo debido a su sexualidad. Peter Tatchell señaló: “Uno de los mayores temas será el maltrato del gobierno para con los gay y las lesbianas que buscan asilo").

28 FELLMETH, supra, en 815.

29 ĺd.

30 Íd.

31 BAYER, K. Gay asylum seeker to be thrown out of UK. [En Línea] Scotland on Sunday, 6 de julio de 2008. <http:// scotlandonsunday.scotsman.com/scotland/Gay-asylum-seeker-to-be.4260491.jp>

32 Íd. El fallo provino del Tribunal de Asilo e Inmigración, que sesionó en Glasgow.

33 íd. 
que: "El gobierno está perdiendo rápidamente su fama de cordialidad ante los gay a consecuencia de sus malos tratos vengativos, crueles e insensibles de los gay que desean obtener asilo" ${ }^{\prime 34}$.

En consecuencia, los casos de asilo continúan situándose en una brecha normativa entre las normas de Europa y las de gran parte del resto del mundo. De hecho, en octubre de 2008, Lin Homer, Directora del Departamento de Fronteras del Reino Unido, reiteró la posición del gobierno de que la prohibición contra la homosexualidad en el país de origen no es una razón en sí misma para no deportar a alguien que solicita asilo por temor a la persecución a causa de su orientación sexual. Homer señaló que los jueces debían considerar las "consecuencias prácticas" del regreso, no el enfoque jurídico o social de un país respecto de la homosexualidad. "La simple presencia de una ley o de una cultura que ve con malos ojos la homosexualidad no es una razón en sí misma [para otorgar asilo]"35. John Wilkes, Director Ejecutivo del Consejo de Refugiados de Escocia, calificó lo anterior como "una forma de pensar turbia e incoherente", y elaboró una potente analogía: "Si hubiera una ley en un país que estableciera que uno no puede ser judío o miembro del Partido Comunista, ¿el gobierno del Reino Unido los enviaría de vuelta a dicho país para que fueran enjuiciados? Afirmar que alguien no debiera poder expresarse sin ser objeto de persecución es contrario al Convenio Europeo sobre Derechos Humanos y la Convención sobre los refugiados".

\section{Dilemas subyacentes}

Estas discusiones reflejan la situación poco clara de estos casos y de la subyacente interpretación sobre la legislación de derechos humanos y sobre la teoría del asilo. Por una parte, como se señaló, hay una tendencia legislativa significativa sobre derechos humanos que respalda los derechos de los LGBT. En efecto, el 19 de diciembre de 2008, 66 naciones ${ }^{36}$ dieron su apoyo, en la Asamblea General de la ONU, a una declaración que confirmaba que la protección de los derechos humanos internacionales incluía la orientación sexual y la identidad de género ${ }^{37}$. La declaración reafirmó el "principio de no discriminación, que exige que los derechos humanos se apliquen por igual a todos los seres humanos, independientemente de su orientación sexual o identidad de género". Los 66 países declararon estar "profundamente preocupados por las violaciones de derechos humanos y libertades fundamentales basadas en la orientación sexual o identidad de género", y dijeron que "la violencia, acoso, discriminación, exclusión, estigmatización y prejuicio se dirigen en contra de las personas en todos los países del mundo por causa de la orientación sexual o identidad de género". La declaración condenó específicamente los asesinatos, tortura, arresto arbitrario y la "denegación de los derechos económicos, sociales y culturales, incluyendo el derecho a la salud". Exhortó a todas las naciones a que "se comprometan con la promoción y protección de los derechos humanos de todas las personas, independientemente de su orientación

34 ld.

35 HOWIE, M. Homosexuality ban no reason for asylum. The Scotsman, 11 de octubre de 2008.

36 Los estados signatarios son: Albania, Andorra, Argentina, Armenia, Australia, Austria, Bélgica, Bolivia, Bosnia y Herzegovina, Brasil, Bulgaria, Canadá, Cabo Verde, República Centroafricana, Chile, Colombia, Croacia, Cuba, Chipre, República Checa, Dinamarca, Ecuador, Estonia, Finlandia, Francia, Gabón, República de Georgia, Alemania, Grecia, República de Guinea-Bissau, Hungría, Islandia, Irlanda, Israel, Italia, Japón, Letonia, Principado de Liechtenstein, Lituania, Luxemburgo, Malta, República de Mauricio, México, Montenegro, Nepal, los Países Bajos, Nueva Zelanda, Nicaragua, Noruega, Paraguay, Polonia, Portugal, Rumania, San Marino, República Democrática de Santo Tomé y Príncipe, Serbia, Eslovaquia, Eslovenia, España, Suecia, Suiza, Antigua República Yugoslava de Macedonia, República Democrática de Timor Oriental, Reino Unido, Uruguay y Venezuela.

37 Inicialmente, la Santa Sede se había opuesto a la declaración de la Asamblea General. Sin embargo, a raíz de fuertes críticas de parte de los defensores de los derechos humanos en todo el mundo, la Santa Sede indicó a la Asamblea General que apoyaba la derogación de las sanciones penales para las conductas homosexuales. 
sexual e identidad de género", y a poner fin a las sanciones penales en contra de las personas por causa de su orientación sexual o identidad de género.

El Comité de Derechos Humanos de las Naciones Unidas, que interpreta el Pacto Internacional sobre Derechos Civiles y Políticos (PIDCP), sostuvo en 1994 que dichas leyes constituyen violaciones de derechos, y que las normas internacionales sobre derechos humanos prohíben la discriminación basada en la orientación sexual. Muchos otros organismos internacionales se han opuesto a la violencia y la discriminación basada en la orientación sexual y la identidad de género, incluidos el Consejo de Europa y la Unión Europea. En el año 2008, los 34 países integrantes de la Organización de los Estados Americanos aprobaron unánimemente una declaración afirmando que la protección de los derechos humanos se extiende a la orientación sexual y la identidad de género. Sin embargo, al menos setenta países aún tienen leyes en contra de las relaciones sexuales consensuadas entre adultos del mismo $\operatorname{sexo}^{38}$, y la discriminación -tanto con o sin aprobación jurídica- abunda en todo el mundo ${ }^{39}$.

Ciertamente no hay un consenso moral subyacente acerca de las relaciones entre personas del mismo sexo en el contexto del matrimonio. El Papa Benedicto XVI desencadenó un gran debate en un discurso pronunciado en la Navidad del año 2008, en que se refirió críticamente al concepto de "género" y la responsabilidad de la Iglesia que "no sólo debe defender la tierra, el agua y el aire como dones de la creación [sino] también debe proteger al hombre contra la destrucción de sí mismo". Señaló que es necesario que haya "algo como una ecología del hombre, [que implica] la naturaleza del ser humano como hombre y mujer, y pide que se respete este orden de la creación,... cuyo desprecio sería una autodestrucción del hombre y, por tanto, una destrucción de la obra misma de Dios" ${ }^{\prime 40}$.

En Estados Unidos, pese a opiniones jurídicas innovadoras, como la del juez Anthony Kennedy en el caso Lawrence versus Texas ${ }^{41}$, la discusión jurídica y moral respecto de las relaciones entre personas del mismo sexo está lejos de resolverse. Una ley federal, la Ley de Defensa del Matrimonio, define el "matrimonio" como "sólo una unión legal entre un hombre y una mujer como marido y mujer", y "cónyuge" como "solamente una persona del sexo opuesto que es marido o mujer" ${ }^{42}$.

El Estado de California estuvo dividido por un intenso debate en torno a la Proposición 8, que modificó la Constitución del Estado con el fin de limitar la definición del matrimonio a una unión entre un hombre y una mujer, además de derogar el derecho de las parejas del mismo sexo a contraer matrimonio ${ }^{43}$. Algunos de sus defensores se han referido a tal derecho como "un problema de sobrevivencia" en la "guerra de la cultura" ${ }^{44}$. El pastor Rick Warren, invitado por el presidente electo Obama para pronunciar la oración en la ceremonia de inauguración, hizo una analogía del matrimonio gay con el matrimonio entre un hermano y una hermana, o entre un adulto y un

\footnotetext{
38 Ver http://www.hrw.org/en/reports/2008/12/17/alien-legacy-0. Ver también UNHCR Guidance Note, supra p. 4; International Gay and Lesbian Human Rights Commission, (http://www.iglhrc.org/site/iglhrc/) y SodomyLaws.org (http:// www.sodomylaws.org/) (que menciona 80 países similares).

39 FELLMETH, supra, en 835; ver, OTTOSSON, supra; World Legal Survey, supra.

40 Discurso del Santo Padre a la Curia; disponible en: http://www.zenit.org/article-24682? l=English

41539 U.S. 558 (2003) (declara inaplicable la ley de sodomía de Texas, sosteniendo que las conductas íntimas consensuadas entre adultos son parte de la libertad protegida por el debido proceso sustantivo según la Decimocuarta Enmienda).

42 Public Law No 104-199, 110 Stat. 2419 (1996).

43 El referéndum fue diseñado para anular algunos de los fallos de la Corte Suprema de California en In re Marriage Cases. Agregó una nueva sección constitucional que establece que: "Sólo el matrimonio entre un hombre y una mujer es válido o reconocido en California".

44 Ver http://www.protectmarriage.com/testimonials
} 
niño. Su Iglesia ha señalado que las personas gay, que "no tienen la disposición de arrepentirse de su estilo de vida homosexual, no serían aceptadas" como miembros de la congregación ${ }^{45}$.

Analicemos los extractos de un informe periodístico ${ }^{46}$ sobre un caso pionero en Australia: el primero en que una Corte de Apelaciones, en segunda instancia, sostuvo (por 4 votos a favor $y$ 3 en contra) que las peticiones de asilo basadas en la orientación sexual podían ser sometidas al conocimiento judicial. Una organización cristiana "advirtió que la sentencia provocaría una avalancha de peticiones de personas que no eran refugiados sino que simplemente habían escogido un estilo de vida particular". El grupo, Salt Shakers, declaró que: "Esta decisión establecerá un precedente muy peligroso, puesto que en todos los países musulmanes hay personas que eligen ser homosexuales, y el Islam lo prohíbe. Si el Tribunal de Refugiados acepta la decisión del Tribunal Superior, todos ellos querrán venir aquí". Stokes señaló que los dos peticionarios no eran refugiados y que Australia no debía ser obligada a permitirles permanecer en el país. "¿Y qué si se sienten atraídos el uno por el otro? Nadie los obliga a hacer pública ostentación de sus preferencias personales" ${ }^{\prime \prime 7}$.

Del extracto anterior podemos ver cómo el problema del asilo basado en la orientación sexual implica muchas de las tensiones más profundas, enterradas bajo la superficie de la legislación sobre derechos humanos en general y las leyes sobre refugio y asilo en particular. Las mayores tensiones, esbozadas resumidamente, y con las disculpas del caso por la excesiva simplificación, son las siguientes:

- Orientación versus acción: las leyes de asilo tienden a desafiar una actitud comúnmente sostenida por muchos conservadores religiosos respecto de la homosexualidad. "No tengo problemas con la homosexualidad -dijo una vez el senador Rick Santorum de Pensilvania. Tengo problemas con los actos homosexuales" ${ }^{48}$. Según observamos anteriormente, Jacqui Smith se inclinó en la misma dirección, como lo han hecho los jueces de asilo del Reino Unido. Irónicamente, es difícil pensar que esta sería una afirmación que los conservadores religiosos sostendrían en solicitudes de asilo por motivos religiosos. ¿Puede la ley diferenciar legítimamente la "disposición" del comportamiento personal? Por ejemplo, ¿puede un juez de asilo decirle a un disidente político o a un miembro de una minoría religiosa perseguida que no debería tener problemas si simplemente se reserva sus opiniones o rechaza practicar su fe? Si no es así, ¿por qué una decisión de este tipo es legítima cuando se aplica a la orientación sexual?

- "Naturaleza versus formación": parte de la respuesta al problema de la "orientación versus acción" depende de la manera como se entiende la identidad sexual: es decir, ¿la orientación sexual se entiende como inherente a la propia personalidad, como una cuestión de elección o una combinación de ambas? ¿Y qué depende de esta caracterización?

- El modelo del grupo minoritario y la "esencialización" de la sexualidad: Una fuerte teoría subyacente trata a los homosexuales como "un grupo más o menos homogéneo que requiere

\footnotetext{
45 Ver, ABC NEWS. Rick Warren: Not Anti-Gay to Oppose Gay Marriage. [En Línea] ABC News, 23 de diciembre de 2008. <http://abcnews.go.com/US/WireStory?id=6520003\&page $=2>$

46 GOODENOUGH, P. Court Rules in Favor of Homosexual Asylum-Seekers. [En Línea] CNSNews.com, 11 de diciembre de 2003. <http://www.newsbull.com/forum/topic.asp?TOPIC_ID=9424>

47 ld.

48 Entrevista, Associated Press, 21 de abril de 2003.
} 
protección" ${ }^{49}$. Así, el Tribunal Europeo de Derechos Humanos ha comparado específicamente la homofobia con el racismo, en el contexto del reclutamiento militar:

"En la medida en que [las normas legales] representan un prejuicio por parte de una mayoría heterosexual en contra de una minoría homosexual, estas actitudes negativas no pueden, de por sí, ser consideradas por un Tribunal, como justificación suficiente... del mismo modo que no pueden serlo actitudes negativas similares hacia las personas de una raza, origen o color diferente $\mathrm{e}^{\prime 50}$.

- Aunque este modelo puede armonizar bien con las prohibiciones tradicionales en contra de la discriminación arbitraria hacia "grupos minoritarios", plantea ciertas complejidades, especialmente para los bisexuales ${ }^{51}$. En efecto, se tendería a esencializar la sexualidad de un modo que no se condice con las complejidades de la gente real. Por ejemplo, podría Ilegar a exigirse que se pruebe que una persona "es" gay, lesbiana o transexual, implícitamente sosteniendo que se trata de una cuestión binaria. Como plantea un importante manual de práctica de EE.UU., "en la preparación de una petición de asilo basada en la orientación sexual, es esencial recordar que el primer elemento que debe probarse ante el juez es que el solicitante realmente es lesbiana o gay ${ }^{52}$. Además, surge el problema de que otros indicadores de estatus del grupo minoritario implican características físicas y no conductas. De modo que esta aproximación repite el dilema de la orientación versus la acción. El problema se vuelve bastante tangible cuando uno considera los contornos y limitaciones de una categoría de "grupo social específico".

- Universalismo versus relativismo: ¿En qué medida sería legítimo que los derechos humanos y las leyes de asilo se subordinaran a distintas concepciones sobre la moralidad respecto de ciertos tipos de comportamiento sexual? Como se señaló anteriormente, dista mucho de haber un consenso moral acerca de la homosexualidad, incluso en Estados que podrían conceder el asilo sobre esta base. El senador Rick Santorum sostuvo una vez que: "Si el Tribunal Supremo dice que uno tiene derecho al sexo (gay) consensuado al interior de su hogar, entonces uno tiene derecho a la bigamia, a la poligamia, al incesto y al adulterio. Uno tiene derecho a cualquier cosa". Una manera de resolver esto -al menos parcialmente-, como sugirió en una ocasión Arthur Helton, es considerar la decisión de asilo como un acto de Estado, realizado por los jueces que fallan estos casos dentro de la jurisdicción territorial de Estados Unidos. Así, en este escenario: "[Es] nuestra cultura jurídica la que rige". Esto, sugirió, "debiera cambiar los términos del debate sobre el relativismo cultural" ${ }^{53}$. Por supuesto, esta posición es útil. Sin embargo, simplemente distingue las leyes de asilo de los demás cuerpos legislativos sobre derechos humanos y no resuelve la tensión de fondo.

- El encasillamiento en un estereotipo por parte de los abogados: La tensión a que nos hemos venido refiriendo se presenta también en el modo como los abogados suelen argumentar los casos sobre asilo. Es frecuente que se den profundos problemas de encasillamiento en un estereotipo en las peticiones de asilo de los LGBT. Como observó Jacqueline Bhabha: "Si el objetivo es obtener asilo, son innecesarios los análisis sociales matizados respecto del país

49 FELLMETH, supra, en 874.

50 FELLMETH, supra, en 876; Lustig-Prean, 29 Eur. H.R. Rep. en 90; Smith \& Grady, 29 Eur. H.R. Rep. en 97.

51 Ver GRIGOLO, M. Sexualities and the ECHR: Introducing the Universal Sexual Legal Subject. European Journal of International Law. 14(5): 1023, 1031-32, 1039-40. 2003.

52 Immigration Equality. LGBT/HIV Asylum Manual. [En Línea] <http://immigrationequality.org/manual_template.php?id=1199> Énfasis agregado.

53 HELTON, A. Simposio: Shifting Grounds For Asylum: Female Genital Surgery And Sexual Orientation. Columbia Human Rights Law Review. 29: 467, 474-5. 1998. 
de origen o el de acogida. Es la ley en sí misma la que exige categorías reconocibles en las que cada caso debe encajar, de modo que las estrategias de simplificación y encasillamiento en un estereotipo se vuelven necesarias" ${ }^{54}$. No obstante, la tendencia de algunos abogados de asilo de presentar los casos mediante excesivas generalizaciones o estereotipos también puede reflejar "un enfoque problemático... aunque con tintes de superioridad moral respecto de los derechos humanos; esto es, un enfoque que construye y cosifica una 'cultura' opresiva, un grupo étnico o una identidad religiosa, en contra de la cual ventilar la indignación sobre la base de normas absolutas y universales..." 55 .

- Normas sociales y leyes discriminatorias de aplicación general: ¿Hasta qué punto puede un Estado ignorar la concepción del individuo sobre su propia autonomía? ${ }^{56}$ Como se señaló anteriormente, la tendencia en la legislación sobre derechos humanos de Europa, y también de otros lugares, es imponer pesadas cargas de justificación a los Estados que discriminan en contra de ciertas formas de conducta. Si la conducta es dañina, como sucede, por ejemplo, con el sexo sadomasoquista, es más probable que se acepte la prohibición ${ }^{57}$. Sin embargo, ¿en qué medida debiera subordinarse el asilo a justificaciones que enarbole el Estado sobre la base de normas culturales o religiosas? Claramente, el sometimiento total a las creencias de la mayoría priva por completo de sentido a la misión de los derechos humanos y vuelve inaccesible al asilo, salvo quizás en los casos de penas desproporcionadas. Sin embargo, de lo anterior queda claro que incluso el régimen de asilo más liberal que prevalece en Europa sigue luchando con las cuestiones-límite que presenta este problema.

- "Enjuiciamiento" versus "persecución": Específicamente, ¿constituye la posibilidad de enjuiciamiento (o la existencia de leyes penales) en contra de la conducta homosexual un fundamento per se para otorgar asilo? Como se señaló anteriormente, muchos tribunales son renuentes a aceptar plenamente este criterio. No obstante, es necesario entonces responder a la pregunta de por qué la distinción entre enjuiciamiento y persecución sería aceptable en estos casos, cuando ciertamente se rechazaría tratándose, por ejemplo, de casos religiosos. Quizás la interrogante precedente podría contestarse haciendo referencia a factores tales como la prevalencia de los enjuiciamientos y el carácter (des)proporcionado de la pena. Como concluyera en una oportunidad la Corte Suprema de Canadá respecto de la política china de "un solo niño por pareja": "[Bajo] ciertas circunstancias, una ley de aplicación general puede constituir persecución... La brutalidad en la prosecución de un fin legítimo sigue siendo brutalidad"58. Sin embargo, este enfoque no soluciona la disonancia acerca de si las leyes de asilo deberían aceptar o no la legitimidad de cualesquiera leyes contrarias a los gay o sus prácticas.

- Derecho y política: Lo fundamental y final es ¿cómo conciliamos los componentes políticos con los aspectos legales de los problemas planteados anteriormente? Estamos frente a un enorme trabajo en desarrollo, en que las decisiones adoptadas en un escenario de derechos humanos pueden tener profundas repercusiones en otros ${ }^{59}$. Hace una década, al observar estos

54 BHABHA, supra; ver también, MAMDANI, M. (Ed.) Beyond Rights Talk and Culture Talk.

55 BHABHA, supra, en 164.

56 Ver BOLAND, R. Civil and Political Rights and the Right to Nondiscrimination: Population Policies, Human Rights, and Legal Change. American University Law Review. 44:1257,1270. 1995.

57 Ver, por ejemplo, Laskey, Jaggard \& Brown v. United Kingdom, 24 Eur. H.R. Rep. 39 (1997).

58 Cheung v. Canada (Ministerio del Trabajo e Inmigración) [1993] 102 D.L.R. 4th 214 (Can.); cf. Matter of G-, Interim Decision 3215 (BIA 1993).

59 Como ha señalado Jacqueline Bhabha: "El campo de los derechos humanos ha experimentado una transformación importante desde mediados del siglo veinte, cuando se estableció el principal marco normativo para el derecho internacional de los refugiados. Un enfoque basado en el género respecto de los derechos ha transformado la forma de 
hechos entonces incipientes, Arthur Helton se preguntaba si era mejor entenderlos como "un cambio sísmico, un terremoto o... un lento incremento, más parecido al desplazamiento de las placas continentales acercándose mutuamente". Aunque la jurisprudencia emergente ha respondido varias de estas interrogantes, muchas de las cuestiones más importantes siguen aún sin solución definitiva ${ }^{60}$.

pensar acerca de lo que se considera una violación de derechos, problematizando no sólo la división simplista entre el daño público, inducido por el Estado, y los problemas privados de origen doméstico, sino también la mismísima noción de lo 'político'. De este modo, el discurso de los derechos humanos se ha transformado para incluir materias relativas a las costumbres sociales, la orientación sexual y la sexualidad, desde un perspectiva de género".

60 HELTON, A. Simposio: Shifting Grounds For Asylum: Female Genital Surgery And Sexual Orientation. Columbia Human Rights Law Review. 29:467,476. 1998. 
